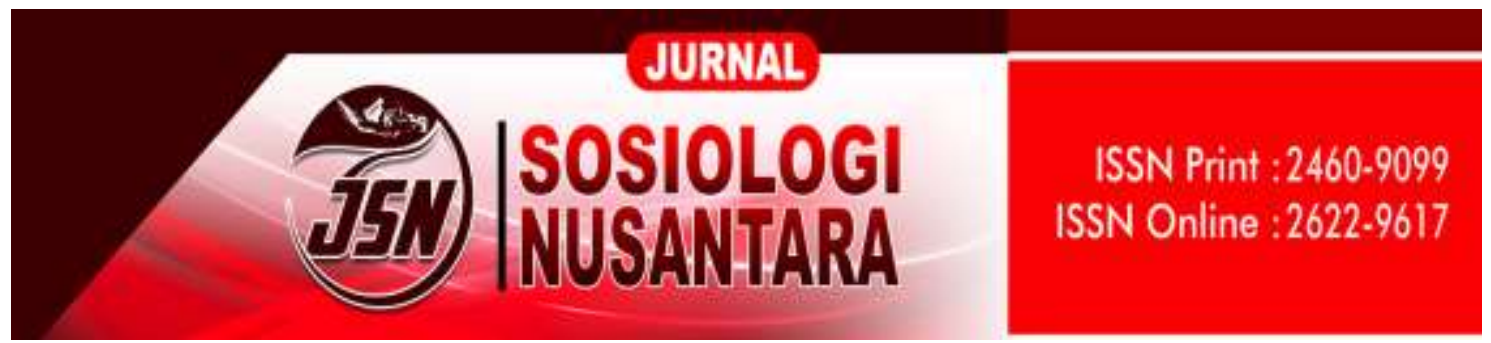

\title{
PARTISIPASI MASYARAKAT \\ DALAM KELOMPOK KEGIATAN PROGRAM KAMPUNG KB MAKMUR DESA ARISAN GADING, KABUPATEN OGAN ILIR
}

\section{COMMUNITY PARTICIPATION IN THE PROGRAM ACTIVITY GROUP OF THE KAMPUNG KB MAKMUR VILLAGE OF ARISAN GADING, OGAN ILIR REGENCY}

\author{
Triana Putri Siregar1, Yunindyawati², Nengyanti ${ }^{3}$ \\ trianaputrisiregar@gmail.com \\ 1,2,3Fakultas Ilmu Sosial dan Ilmu Politik, Universitas Sriwijaya
}

\begin{abstract}
Abstrak
Penelitian ini di latar belakangi dari adanya penurunan partisipasi masyarakat dalam kegiatan program Kampung KB yaitu Bina Keluarga Balita (BKB), Bina Keluarga Remaja (BKR), Bina Keluarga Lansia (BKL), dan Usaha Peningkatan Pendapatan Keluarga Sejahtera (UPPKS). Tujuan penelitian ini adalah menganalisis penurunan partisipasi masyarakat dalam kelompok kegiatan Kampung KB. Teori yang digunakan adalah teori partisipasi masyarakat dari Cohen dan Uphoff (1977) yang dilihat dari empat tahap partisipasi yaitu tahap perencanaan, tahap pelaksanaan, tahap menikmati hasil dan tahap evaluasi. Metode penelitian menggunakan kualitatif dengan unit analisis data yaitu masyarakat. Adapun teknik pengumpulan data menggunakan observasi, wawancara mendalam, dan dokumentasi. Hasil penelitian menunjukkan bahwa penurunan partisipasi masyarakat dalam kelompok kegiatan Kampung KB disebabkan oleh kurang mendapat informasi dan sosialisasi tentang kegiatan Kampung KB, penyampaian penyuluhan kurang menarik dan tidak dimengerti masyarakat, kurangnya anggaran dana, tempat pelaksanaan penyuluhan yang berubah-ubah, penyelenggaraan kegiatan dilaksanakan pada jam kerja, kurangnya kesadaran masyarakat, sarana dan prasarana yang kurang memadai, dan jarak kegiatan yang jauh dari rumah. Adapun temuan yang diperoleh dalam penelitian ini adalah adanya model pengembangan masyarakat melalui tahap advokasi setelah tahap perencanaan agar masyarakat merasa penting bahwa partisipasi masyarakat dibutuhkan dalam menjalankan program pemerintah.
\end{abstract}

Kata kunci : Kampung KB, Partisipasi, Pola Partisipasi. 


\begin{abstract}
This research is based on a decrease in community participation in the activities of the Family Planning Village program, namely Family Development for Toddlers (BKB), Community Development for Youth Families (BKR), Elderly Family Development (BKL), and Efforts to Increase Prosperous Family Income (UPPKS). The purpose of this study was to analyze the decrease in community participation in the group activities of the KB Village. The theory used is the theory of community participation from Cohen and Uphoff (1977) which is seen from the four stages of participation, namely the planning stage, the implementation stage, the enjoyment stage and the evaluation stage. The research method used qualitative with the data analysis unit, namely the community. The data collection techniques used observation, in-depth interviews, and documentation. The results showed that the decrease in community participation in the Kampung KB activity group was caused by lack of information and socialization about the activities of the $K B$ Village, the delivery of counseling was less attractive and not understood by the community, lack of budget funds, changing places for the implementation of the counseling, the implementation of activities was carried out at work, lack of public awareness, inadequate facilities and infrastructure, and activities are far from home. The findings obtained in this study are the existence of a community development model through the advocacy stage after the planning stage so that the community feels it is important that community participation is needed in carrying out government programs.
\end{abstract}

Keywords: KB Village, Participation, Participation Patterns.

\title{
PENDAHULUAN
}

Pembangunan menjadi kunci menuju kesejahteraan masyarakat. Jika dilihat sekarang pembangunan di Indonesia belum merata. Mereka masih banyak memerlukan fasilitas-fasilitas yang layak. Pembangunan adalah proses yang historical (Gunawan, 2005). Selain itu pembangunan juga diartikan sebagai usaha yang terencana dan melembaga yang meliputi bentuk intervensi sosial dan pelayanan sosial untuk memenuhi kebutuhan manusia, mencegah dan mengatasi masalah sosial serta memperkuat institusi-institusi sosial (Edi, 2014).

Dalam rangka mensejahterahkan masyarakat di Indonesia, pemerintah sudah berupaya dengan memberikan berbagai program, salah satunya yaitu program Keluarga Berencana (KB) dan Kampung Keluarga Berencana (KB). Berdasarkan data yang diperoleh dari BKKBN Kabupaten Ogan Ilir. Salah satu desa yang menjalankan program kampung KB adalah Desa Arisan Gading.

Berdasarkan observasi dapat diketahui bahwa awalnya kegiatan ini banyak diminati oleh masyarakat. Dilihat dari kegiatan Bina Keluarga Balita (BKB), Bina Keluarga Remaja (BKR), Bina Keluarga Lansia (BKL) dan Usaha Peningkatan 
Pendapatan Keluarga Sejahtera (UPPKS). Adapun jumlah yang aktif mengikuti kegiatan ini sebagai berikut:

Tabel 1 Jumlah Kehadiran Aktif Masyarakat Dalam Kegiatan

\begin{tabular}{ccccc}
\hline Kampung & \multicolumn{4}{c}{ Hadir Aktif Mengikuti Pertemuan } \\
\cline { 2 - 5 } & BKB & BKR & BKL & UPPKS \\
\hline I & 4 & 10 & 3 & 12 \\
\hline II & 18 & 15 & 9 & 23 \\
\hline III & 15 & 12 & 12 & 22 \\
\hline IV & 0 & 0 & 0 & 71 \\
\hline Jumlah & 37 & 37 & 24 &
\end{tabular}

Sumber : Data Kegiatan Kampung KB Makmur, Tahun 2019

Berdasarkan data diatas bahwa masyarakat yang aktif dalam pertemuan dan kegiatan BKB berjumlah 37 orang, dengan jumlah keluarga yang menjadi sasaran dalam kegiatan BKB berjumlah 65 orang. Kegiatan BKR berjumlah 37 orang, dengan jumlah keluarga yang menjadi sasaran dalam kegiatan BKR berjumlah 148 orang. Kegiatan BKL berjumlah 24 orang, dengan jumlah keluarga yang menjadi sasaran dalam kegiatan BKL berjumlah 51 orang, serta kegiatan UPPKS berjumlah 71 orang dengan jumlah keluarga yang menjadi sasaran dalam kegiatan UPPKS adalah 192 orang.

Tabel 2 Partisipasi Masyarakat Dalam Poktan (Kelompok Kegiatan)

\begin{tabular}{c|c|c}
\hline \multirow{2}{*}{ Kelompok Kegiatan (Poktan) } & \multicolumn{2}{|c}{ Tahun } \\
\cline { 2 - 3 } & $\mathbf{2 0 1 8}(\boldsymbol{\%})$ & $\mathbf{2 0 1 9}(\mathbf{\%})$ \\
\hline UPPKS & 29,74 & 20,5 \\
\hline BKL & 29,87 & 16,45 \\
\hline BKR & 34,21 & 19,20 \\
\hline BKB & 8,0 & 7,90 \\
\hline
\end{tabular}

Sumber : Data Kampung KB Makmur, Tahun 2019

Berdasarkan data di atas bahwa persentase partisipasi masyarakat dalam kelompok kegiatan Kampung KB tahun 2018 dan 2019 mengalami penurunan. Penurunan ini disebabkan oleh terjadinya pergantian kepala desa, sehingga menyebabkan masyarakat beranggapan bahwa kegiatan dalam program ini belum berjalan seperti tidak adanya pengumuman tentang adanya kegiatan posyandu balita, senam lansia dan beberapa kegiatan lainnya, dikarenakan sebelumnya setiap adanya kegiatan pastinya akan diumumkan kepada masyarakat. serta kurangnya kemauan dan kesadaran dari masyarakat untuk berpartisipasi serta tingkat pendidikan dan pengetahuan. 


\section{METODE PENELITIAN}

Penelitian ini merupakan penelitian kualitatif yang bersifat deskriptif analitik dengan menggunakan unit analisis masyarakat yakni yang terlibat langsung dalam kelompok kegiatan program kampung Keluarga Berencana. Penentuan informan dilakukan secara purposive dengan 10 informan. Teknik pengumpulan data melalui data primer dan data sekunder. Data primer diperoleh berdasarkan observasi dan wawancara terhadap informan penelitian dengan menggunakan pedoman wawancara. Sedangkan data sekunder diperoleh berdasarkan studi pustaka, literatur dan jurnal ilmiah.

\section{PEMBAHASAN}

\section{Penurunan Partisipasi Masyarakat Dalam Kegiatan Usaha Peningkatan Pendapatan Keluarga Sejahtera (UPPKS)}

1. Kurang mendapat informasi dan sosialisasi tentang kegiatan Kampung KB

Pelaksanaan pembelajaran dalam penyelenggaraan kelompok kegiatan ini terdapat tiga unsur, yaitu penyuluhan, sosialisasi, dan keterampilan.

Tabel 3 Penyuluhan Program Kampung KB Makmur

\begin{tabular}{ccc}
\hline Jadwal & Materi & Jumlah Peserta \\
\hline 18 Desember 2017 & Peningkatan Berwirausaha Masyarakat & 71 orang \\
\hline 06 Agustus 2018 & Pengolahan Barang Bekas & 52 orang \\
\hline \multicolumn{2}{c}{ Sumber : Diolah dari data lapangan dan data Kampung KB Makmur, Tahun 2019 }
\end{tabular}

Dari tabel di atas bahwa pelaksanaan kegiatan penyuluhan sudah dilakukan dua kali yaitu tanggal 18 Desember 2017 dan 06 Agustus 2018, dimana materi pembelajaran pada penyuluhan pertama yaitu tentang peningkatan berwirausaha dalam masyarakat dan pengolahan barang bekas tanpa mesin menjadi nilai jual.

2. Penyampaian Penyuluhan Kurang Menarik Dan Tidak Dimengerti Masyarakat

Penyuluhan adalah proses komunikasi yang dilakukan oleh komunikator dan komunikan, dimana dalam proses tersebut terdapat interaksi sosial. Dalam pelaksanaan kegiatan ini masih sangat kurang dikarenakan materi penyuluhan kurang dimengerti masyarakat. Alasan ini disebabkan oleh suara dari komunikator yang kecil sehingga peserta tidak kedengaran. 


\section{Penurunan Partisipasi Masyarakat Dalam Kegiatan BKB}

Tempat dan pelaksanaan penyuluhan yang berubah-ubah

Proses penyuluhan BKB sudah berjalan akan tetapi belum optimal. Hal ini di tandai dengan adanya jadwal dan tempat penyuluhan yang tidak jelas. Selain hal tersebut juga di dalam pelaksanaannya yang seharusnya dapat dilakukan satu bulan sekali itu terkadang tidak berjalan sebagai mana mestinya terkadang perbulannya dapat dilakukan dan terkadang juga ada yang absen (tidak ada penyuluhan). Tempat pelaksanaan penyuluhan yang dominan dilakukan di Balai Desa memiliki karakteristik tempat yang tidak mendukung untuk dilakukan penyuluhan seperti tidak adanya alat pengeras suara serta sempitnya ruangan menjadikan tempat penyuluhan ini sering berubah sehingga menjadikan masyarakat malas untuk mengikuti kegiatan ini.

\section{Penurunan Partisipasi Masyarakat Dalam Kegiatan BKR}

Sarana dan prasarana yang masih kurang memadai dalam kegiatan BKR

Minimnya sarana yang dimiliki oleh kegiatan BKR ini mengakibatnya terhambatnya kegiatan yang akan dilaksanakan. Seperti kurangnya gedung yang dijadikan sebagai tempat pertemuan dan juga pengeras suara, sehingga para peserta kurang terdengar dalam penyampaian kegiatan.

\section{Penurunan Partisipasi Masyarakat Dalam Kegiatan BKL}

1. Kondisi Kesehatan yang Kurang Baik

Pada lansia cenderung erat kaitannya dengan perubahan fisik. Kondisi ini menjadi alasan utama lansia sulit mengikuti kegiatan BKL. Mereka lebih memilih berdiam diri dirumah daripada mengikuti kegiatan ini.

2. Jarak kegiatan yang jauh dari rumah

Kurangnya informasi menjadikan lansia tidak bisa berpartisipasi langsung dalam kegiatan BKL. Hal ini dikarenakan lokasi kegiatan yang jauh dari rumah sehingga menyebabkan lansia lebih memilih berdiam diri di rumah daripada mengikuti kegiatan BKL ini.

Dalam melaksanakan program kegiatan ini, masyarakat terbagi menjadi 4 kelompok berdasarkan usia masyarakat. Seperti masyarakat yang memiliki balita wajib mengikuti kegiatan Bina Keluarga Balita. Masyarakat yang memiliki remaja wajib mengikuti kegiatan Bina Keluarga Remaja. Masyarakat yang sudah mencapai usia 60 tahun ke atas juga di wajibkan untuk mengikuti kegiatan Bina Keluarga Lansia. 
Sedangkan ibu-ibu rumah tangga juga diwajibkan untuk mengikuti kegiatan Usaha Peningkatan Pendapatan Keluarga Sejahtera. Pelaksanaan kelompok kegiatan tersebut dinilai belum efektif dikarenakan masih jarang dilakukan sehingga mengakibatkan masyarakat menjadi acuh tak acuh. Dalam hal ini khususnya dalam tahap pelaksanaan dimana masyarakat desa Arisan Gading dalam hal program Kampung KB masyarakat sangat minim dalam arti keinisiatifan masyarakat dalam suatu kegiatan sangat rendah, begitu juga dalam partisipasi masyarakat kurang ada inisiatif dari dalam diri masyarakat untuk terlibat dalam kegiatan, masyarakat terkesan menunggu komando dari pemerintah daripada adanya inisiatif sendiri dari dalam diri untuk terlibat dalam kegiatan.

Di Desa Arisan Gading ini adanya pelayanan medis KB gratis (TKBK) yang dilaksanakan oleh Dinas Pengendalian Penduduk dan Keluarga Berencana (DP2KB) Kabupaten Ogan Ilir dalam rangka meningkatkan jumlah akseptor KB di Kampung KB desa Arisan Gading (J.M, 1977)

Pelaksanaan kelompok kegiatan dinilai belum efektif dikarenakan masih jarang dilakukan sehingga mengakibatkan masyarakat menjadi acuh tak acuh. Dalam hal ini khususnya dalam tahap pelaksanaan dimana masyarakat desa Arisan Gading dalam hal program Kampung KB masyarakat sangat minim dalam arti keinisiatifan masyarakat dalam suatu kegiatan sangat rendah, begitu juga dalam partisipasi masyarakat kurang ada inisiatif dari dalam diri masyarakat untuk terlibat dalam kegiatan, masyarakat terkesan menunggu komando dari pemerintah daripada adanya inisiatif sendiri dari dalam diri untuk terlibat dalam kegiatan.

Pendekatan yang perlu dilakukan oleh pemerintah kepada masyarakat adalah melalui tahap advokasi, pengembangan partisipasi masyarakat dalam kelompok kegiatan Kampung KB diperlukan tahap advokasi setelah adanya tahap perencanaan, masyarakat dituntut ikut berpartisipasi dalam program yang diberikan pemerintah kepada masyarakat. Pemerintah desa akan melibatkan seluruh lapisan masyarakat baik pemuka agama, tokoh adat, para tenaga pengajar dan juga pemuda untuk bermusyawarah terkait pembangunan yang akan dilaksanakan pada tahun mendatang. dan memberikan kepercayaan masyarakat untuk ikut berpartisipasi dalam hal pembangunan agar pemerintah desa dan masyarakat saling bekerjasama sehingga tidak ada kecurigaan masyarakat kepada pemerintah desa dan yang lebih penting lagi adanya transparansi antara pemerintah desa dan masyarakat. Selain itu, pemerintah desa dapat 
meningkatkan inisiatif masyarakat termasuk kemandirian, dikarenakan selama ini masyarakat hanya bisa mengandalkan pemerintah desa tanpa adanya inisiatif sendiri untuk melakukan kegiatan.

\section{KESIMPULAN}

Penurunan partisipasi pada kegiatan BKB yaitu tempat penyuluhan yang berubah-ubah, penyelenggaraan kegiatan dilaksanakan pada jam kerja (kurang efektif). Pada kegiatan BKR yaitu kurangnya kesadaran ibu-ibu Pasangan Usia Subur (PUS) untuk ikut berpartisipasi dalam kegaiatan BKR, dan saranan dan prasarana yang masih kurang memadai dalam kegiatan BKR. Pada kegiatan BKL yaitu kondisi kesehatan yang kurang baik dan jarak kegiatan yang jauh dari rumah. Pada kegiatan UPPKS yaitu kurang mendapat informasi dan sosialisasi tentang kegiatan kampung KB serta penyampaian penyuluhan kurang menarik dan tidak dimengerti masyarakat. Partisipasi masyarakat pada kampung KB Makmur dilihat tahap perencanaan, tahap pelaksanaan, tahap menikmati hasil dan tahap evaluasi di lapangan tidak sesuai dengan tujuan dari pelaksanaan Kampung KB. Hal tersebut di sebabkan masih banyaknya kendala dalam melaksanakan program Kampung KB. Maka dari itu, perlu adanya model pengembangan masyarakat melalui tahap advokasi setelah tahap perencanaan agar masyarakat menjadi sadar dan merasa penting bahwa partisipasi masyarakat sangat dibutuhkan dalam menjalankan suatu program.

\section{DAFTAR PUSTAKA}

Cohen, J.M, and N. T. Uphoff. 1977. "Rural Development Participation.” New York: Ithaca.

Dwiningrum, Siti Irene Astuti. 2011. Desentralisasi Dan Partisipasi Masyarakat Dalam Pendidikan. Yogyakarta: Pustaka Pelajar.

Gunawan, Sumodiningrat. 2005. Membangun Indonesia Emas: Model Pembangunan Indonesia Baru Menuju Negara-Negara Yang Unggul Dalam Persaingan Global. Jakarta: Gramedia.

Edi, Suharto. 2014. Membangun Masyarakat Memberdayakan Rakyat. Bandung: PT. Refika Aditama. 
Indrajit , Wisnu \& Soimin. 2014. Pemberdayaan Masyarakat dan Pembangunan Gagasan Manajemen Pengembangan Masyarakat untuk Memutus Mata Rantai Kemiskinan.Malang, Jawa Timur : Intrans Publishing.

Khairuddin. 1992. Pembangunan Masyarakat. Yogyakarta: Liberty Mikkelsen B. 2001. Methods for Development Work and Research. Yayasan Obor Indonesia: Jakarta.

Noor, Juliansyah. 2011. Metodologi Penelitian Skripsi, Tesis, disertai Karya Ilmiah. Jakarta: Prenadamedia Group.

Ritzer, George. 2010. Teori Sosiologi. Jakarta: Kencana.

Sastropoetro, Santoso.1990. Partisipasi, Komunikasi, Persuasi dan Disiplin dalam Pembangunan Nasional. Bandung: Alumni.

Scott, John. 2013. Sosiology The Key Concepts. Jakarta: Rajawali Pers. 